Agrotrópica 33(1): 69 - 78. 2021.

Centro de Pesquisas do Cacau, Ilhéus, Bahia, Brasil

\title{
SELETIVIDADE E EFICÁCIA DE HERBICIDAS PARA O CONTROLE DE PLANTAS DANINHAS NA MANDIOCA
}

\author{
José Roberto Antoniol Fontes, Inocencio Junior de Oliveira, Ronaldo Ribeiro de Morais
}

Empresa Brasileira de Pesquisa Agropecuária/Embrapa Amazônia Ocidental. Rodovia AM 010, km 29, Caixa Postal 319 , 69010-970, Manaus, Amazonas.

jose.roberto@embrapa.br

A cultura da mandioca é fonte de alimento e de renda para os agricultores e a interferência de plantas daninhas reduz a produtividade de raízes em até $90 \%$. A ação de controle mais empregada é a manual, com capinas e roçadas, sendo que o uso de herbicidas pode reduzir o custo de produção e aumentar o rendimento operacional. Porém, é necessário avaliar a seletividade e eficácia de controle de herbicidas para o uso seguro desta ação de controle. Os objetivos deste trabalho foram avaliar a seletividade e a eficácia de controle de herbicidas na cultura da mandioca, cultivar BRS Purus, em Argissolo (terra firme) no município de Iranduba, AM. O experimento foi conduzido em um delineamento em blocos ao acaso com quatro repetições e os tratamentos foram os herbicidas clomazone, diuron e oxadiazon aplicados em pré-emergência (PRE) isolados e associados a uma capina ou aplicação dos herbicidas clethodim ou glifosato aplicados em pós-emergência (POS) aos 60 dias após a aplicação dos herbicidas em PRE. Foram incluídas testemunhas com capina aos 30, 60, 90 e 120 dias após o plantio e outra sem capina durante todo o ciclo da cultura. O herbicida clomazone provocou sintoma muito leve e o clethodim não provocou danos visuais nas plantas da cultura. Os herbicidas diuron e oxadiazon e glifosato provocaram danos moderados, mas com recuperação das plantas e sem afetar a produtividade. O controle de plantas daninhas e a produtividade de raízes obtidas com as pulverizações dos herbicidas em PRE associados a capina ou herbicidas aplicados em POS foram equivalentes às obtidas com as capinas realizadas durante o período crítico de competição. A interferência de plantas daninhas durante todo ciclo da cultura reduziu a produtividade de raízes em $91 \%$.

Palavras-chave: Manihot esculenta, matologia, controle químico.

Selectivity and weed control effectiveness with herbicides in cassava. Cassava is staple food and income for smallholders in the Amazon and the weed interference in the crop reduces root yield by up to $90 \%$. Hoeing and slash are the most common weed control actions adopted by farmers. Herbicides reduce the cost of the weed control, saves labor force and have higher operating efficiencies, but selectivity and control efficacy assessments are necessary for the safe use of this technology. The objectives of this study were to evaluate the herbicide selectivity and weed chemical control effectiveness in the cassava crop, BRS Purus variety, in upland. The experiment was conducted out in a randomized block design with four replications and the treatments were clomazone, diuron and oxadiazon applied in preemergence (PRE) alone and associated with one weeding or application of the clethodim or glyphosate applied in post- emergence (POST) at 60 days after application of the herbicides in PRE. Two checks were included: hoeing at 30, 60, 90 and 120 days after planting and weed free during the entire crop cycle. Clomazone caused very mild symptoms and clethodim did not cause visual damage in the crop. The herbicides diuron and oxadiazon (both in PRE) and glyphosate (in POST) caused moderate damages, but with recovery of the plants and did not cause yield reduction. The weed control efficacy and root yields obtained with herbicides applied in PRE and associated with hoeing or herbicides applied in POST were equivalent to those obtained with the hoeing during the critical period of competition. Weed interference throughout the crop cycle reduced root yield by $91 \%$.

Key words: Manihot esculenta,weed science, chemical control. 


\section{Introdução}

A cultura da mandioca (Manihot esculenta) é uma das mais importantes do mundo, cultivada em mais de 100 países, sobretudo por agricultores familiares, e alimento para milhões de pessoas (FAO, 2013). No estado do Amazonas é utilizada como matéria-prima para a produção de farinha e fonte de renda para o agricultor familiar (Dias, 2015). Neste estado, e em outras regiões da Amazônia, os agricultores empregam nível tecnológico baixo, com pouco ou nenhum uso de adubos e defensivos agrícolas acarretando produtividade baixa, de 9,6 $\mathrm{t}$ de raízes ha-1 (IBGE, 2018). Em trabalhos experimentais (melhoramento genético, adubação, manejo de pragas, etc.) conduzidos por órgãos de pesquisa as produtividades atingem $40 \mathrm{t}$ ha $^{-1}$ (Fontes et al., 2014; Alves et al., 2015; Martins et al., 2018).

As plantas daninhas competem com a cultura da mandioca pela luz solar, água e nutrientes e provocam redução de crescimento de plantas e da produtividade de raízes (Aspiazú et al., 2010; Fontes et al., 2014). A planta de mandioca tem crescimento inicial lento, com capacidade limitada de sombreamento da superfície do solo e cultivada com arranjos espaciais que resultam em grande exposição da superfície do solo à radiação solar, permitindo a ocorrência de fluxos contínuos de germinação de sementes e emergência de plantas daninhas, exigindo em muitas situações mais de uma operação de controle (Silva et al., 2012b). Fontes et al. (2014) eliminaram a interferência negativa de plantas daninhas na produtividade de raízes da cultivar BRS Purus com a realização de 4 capinas no período entre 32 e 125 dias após o plantio.

A ação de controle de plantas daninhas mais utilizada pelos produtores rurais amazonenses é manual, por meio de capinas ou roçadas, com rendimento operacional baixo, sem efeito residual sobre o banco de sementes, onerosa em razão da baixa disponibilidade de mão de obra no campo e cansativa (Fontes et al., 2014; Jacovak et al., 2016). Em outras regiões brasileiras e do mundo o controle de plantas daninhas com aplicação de herbicidas é a ação de controle mais empregada, com rendimento operacional e eficácia de controle altos, menor dependência de mão de obra e custo reduzido em relação às capinas (Chikoye et al., 2006; Silva et al., 2009; Silva et al., 2012b; Reshma et al., 2016).
A seletividade e a eficácia de controle são os fatores mais importante na indicação de herbicidas para o controle de plantas daninhas (Scariot et al., 2013). A seletividade de um herbicida é a sua capacidade de provocar o maior nível de dano possível às plantas daninhas levando-as à mínima capacidade de interferência sem provocar danos significativos na cultura (Oliveira Jr. e Inoue, 2011). O nível de seletividade dos herbicidas depende de muitos fatores, sobretudo cultivares, os herbicidas e suas doses e a interação destes com o ambiente os mais relevantes. Considerando a grande diversidade genética de cultivares de mandioca no Brasil, conservadas na forma de etnovariedades em lavouras de pequena escala (Faraldo et al., 2000; Vieira et al. (2008)), as avaliações de seletividade são importantes. Silva et al. (2012a) relataram tolerância elevada da cultivar IAC 12 ao bentazon ( $720 \mathrm{~g}$ i.a ha-1), enquanto Bandeira et al. (2016) relataram tolerância muito baixa da cultivar Aciolina ao mesmo herbicida (576g i.a ha ${ }^{-1}$ ).

Portanto, os objetivos deste trabalho foram avaliar a seletividade de herbicidas e o controle de plantas daninhas na cultura da mandioca, cultivar BRS Purus cultivada em Argissolo no município de Iranduba, Amazonas.

\section{Material e Métodos}

Foi conduzido um experimento no Campo Experimental do Caldeirão, da Embrapa Amazônia Ocidental em Iranduba-AM, para avaliar a seletividade de herbicidas aplicados em pré-emergência (PRE) e pós-emergência (POS) e o controle de plantas daninhas na cultura da mandioca. O clima local é Af, e o solo classificado como Argissolo Vermelho-Amarelo, textura argilosa, cujas características químicas de amostra de solo estão apresentadas na Tabela 1.

Na Figura 1 estão apresentados os dados climáticos registrados durante o período de condução do experimento.

Um dia antes do manejo de solo para a instalação do experimento a comunidade daninha foi caracterizada por meio de levantamento florístico com 25 lançamentos aleatórios de uma armação quadrada vazada de $1 \mathrm{~m}$ de lado. As plantas foram contadas por espécie para estimativa de parâmetros populacionais (Mueller-Dombois \& Ellemberg, 1974). As espécies daninhas identificadas estão listadas na Tabela 2. 
Tabela 1 - Valores de atributos químicos e físicos de amostra composta de solo coletada em camada de 0 $0,2 \mathrm{~m}$ de profundidade. Iranduba, 2018

\begin{tabular}{|c|c|c|c|c|c|c|c|c|c|c|}
\hline \multirow[t]{2}{*}{ pH } & \multirow{2}{*}{$\begin{array}{l}\text { M.O. } \\
\text { g kg-1 }^{-1}\end{array}$} & $\mathbf{P}$ & $\mathbf{K}$ & $\mathrm{Ca}$ & $\mathbf{M g}$ & $\mathbf{V}$ & $\mathbf{m}$ & Areia & Silte & Argila \\
\hline & & \multicolumn{2}{|c|}{$-\mathrm{mg} \mathrm{kg}^{-1}-$} & \multicolumn{2}{|c|}{$--\mathrm{cmol}_{\mathrm{c}} \mathrm{dm}^{-3}---$} & \multicolumn{2}{|c|}{----- \% ----- } & \multicolumn{3}{|c|}{----------- $\mathrm{g} \mathrm{kg}^{-1}$---------- } \\
\hline 5,31 & 35,6 & 12 & 37 & 2,34 & 1,67 & 44,6 & 8,1 & 16 & 19 & 65 \\
\hline
\end{tabular}

pH em água (1:2,5); MO - matéria orgânica (Walkley-Black); P - fósforo e K - potássio (Mehlich-1); Ca - cálcio e MG - magnésio $\left(\mathrm{KCl} \mathrm{1,0} \mathrm{mol} \mathrm{L}^{-1}\right)$; V - saturação por bases; $\mathrm{m}$ - saturação por alumínio.
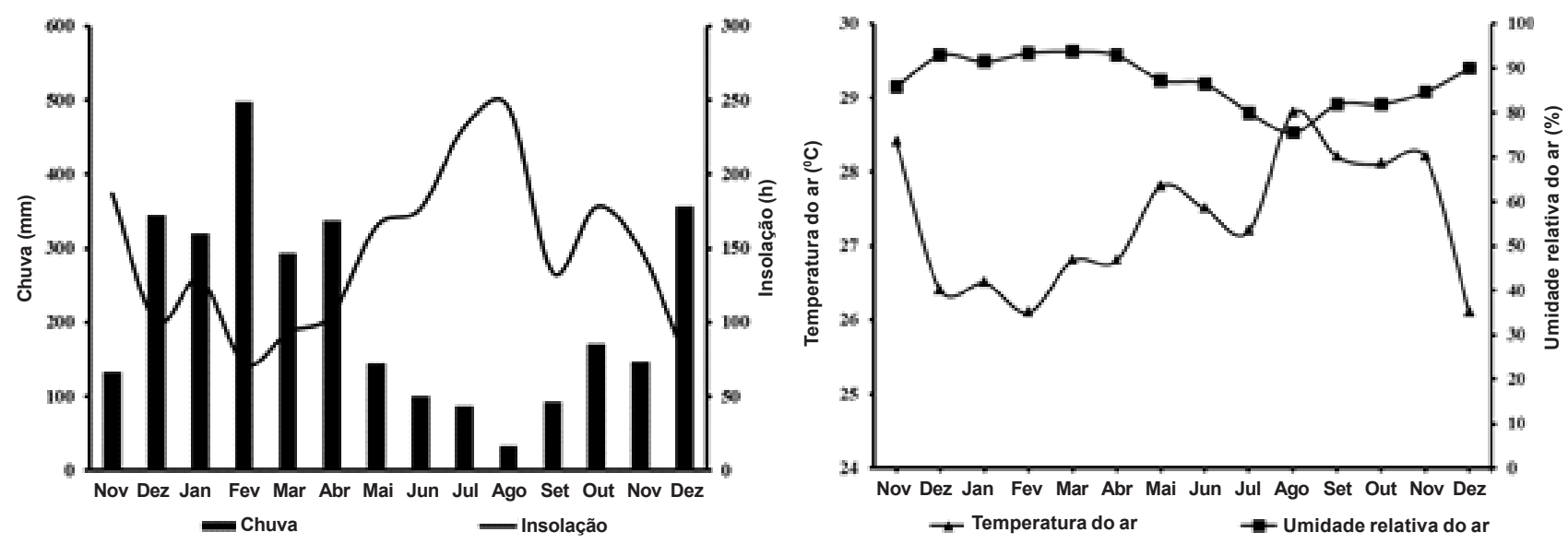

Figura 1 - Valores mensais de chuvas $(\mathrm{mm})$, insolação $(\mathrm{h})$, temperatura do ar $\left({ }^{\circ} \mathrm{C}\right)$ e umidade relativa do ar registradas durante o período de condução do experimento. Iranduba, 2018.

Tabela 2 - Espécies daninhas identificadas na área experimental por ocasião do manejo do solo. Iranduba, 2018

\begin{tabular}{|c|c|c|c|c|c|c|c|c|}
\hline Espécies & Família & D & DR (\%) & $\mathbf{F}$ & FR (\%) & $\mathbf{A}$ & AR (\%) & IIR (\%) \\
\hline Paspalum virgatum & Poaceae & 2,9 & 44,4 & 0,7 & 19,5 & 4,0 & 25,9 & 89,8 \\
\hline Scleria melaleuca & Cyperaceae & 1,0 & 15,8 & 0,7 & 18,5 & 1,5 & 9,7 & 44,0 \\
\hline Croton lobatus & Euphorbiaceae & 0,7 & 10,8 & 0,4 & 11,3 & 1,7 & 10,8 & 32,9 \\
\hline Croton trinitatis & Euphorbiaceae & 0,6 & 8,8 & 0,5 & 14,4 & 1,1 & 7,0 & 30,2 \\
\hline Commelina erecta & Commelinaceae & 0,3 & 5,0 & 0,3 & 9,2 & 1,0 & 6,1 & 20,3 \\
\hline Priva bahiensis & Verbenaceae & 0,3 & 4,2 & 0,3 & 7,2 & 1,0 & 6,7 & 18,1 \\
\hline Cyperus rotundus & Cyperaceae & 0,2 & 3,4 & 0,2 & 6,1 & 1,0 & 6,4 & 15,9 \\
\hline Cleome affinis & Capparaceae & 0,1 & 2,3 & 0,1 & 3,0 & 1,3 & 8,5 & 13,8 \\
\hline Mimosa debilis & Fabaceae & 0,1 & 1,5 & 0,1 & 2,0 & 1,3 & 8,5 & 12,0 \\
\hline Cyperus flavus & Cyperaceae & 0,1 & 1,9 & 0,2 & 5,1 & 0,7 & 4,2 & 11,2 \\
\hline Wedelia paludosa & Asteraceae & 0,1 & 1,5 & 0,1 & 3,0 & 0,9 & 5,7 & 10,2 \\
\hline
\end{tabular}

D - densidade; DR - densidade relativa; F - frequência; FR - frequência relativa; A - abundância; AR - abundância relativa; IIR - índice de importância relativa.

O manejo de solo da área experimental foi realizado com arado de discos numa profundidade de $0,4 \mathrm{~m} \mathrm{e}$ com grade niveladora para eliminação de torrões. A abertura de sulcos de plantio numa profundidade de $0,1 \mathrm{~m}$ e a adubação foram realizadas com sulcadoraadubadora acoplada a trator. A adubação de plantio foi de 50 e $60 \mathrm{~kg} \mathrm{ha}^{-1}$ de $\mathrm{P}_{2} \mathrm{O}_{5}$ e $\mathrm{K}_{2} \mathrm{O}$ nas formas de superfosfato simples e de cloreto de potássio, respectivamente. A cultivar de mandioca escolhida foi a BRS Purus, recomendada para cultivo nas áreas sem inundação periódica (terra firme) e ciclo de 12 a 16 meses (Dias, 2015). Manivas-semente com 0,2 m de comprimento e com 5 a 6 gemas foram depositadas manualmente nos sulcos e cobertas com terra, num 
espaçamento de $1 \mathrm{~m}$ entre fileiras e $0,8 \mathrm{~m}$ entre plantas na fileira. As adubações em cobertura foram parceladas aos 30 e 60 dias após o plantio (DAP) com 20 e $40 \mathrm{~kg} \mathrm{ha}^{-1}$ de $\mathrm{N}$ e de $\mathrm{K}_{2} \mathrm{O}$ na forma de ureia e de cloreto de potássio, respectivamente.

O experimento foi conduzido num delineamento em blocos ao acaso com quatro repetições. A parcela experimental foi formada por 8 fileiras de plantio com $5,6 \mathrm{~m}$ de comprimento cada uma $\left(51,2 \mathrm{~m}^{2}\right)$, com área útil formada pelas quatro fileiras centrais, desconsiderando-se uma planta de mandioca em cada extremidade $\left(23,2 \mathrm{~m}^{2}\right)$. Duas fileiras foram destinadas à avaliação de seletividade e as outras duas à avaliação de controle. Nas fileiras destinadas a avaliação de seletividade o controle de plantas daninhas foi realizado com capinas aos 30, 60, 90 e 120 DAP, durante o período total de prevenção da interferência de plantas daninhas na cultivar BRS Purus (Fontes et al., 2014).

Os tratamentos avaliados no experimento estão listados na Tabela 3. A aplicação dos herbicidas em PRE foi realizada 1 DAP com um pulverizador costal pressurizado com dióxido de carbono e com barra munida com 6 pontas de pulverização 110.02 e espaçadas em $0,5 \mathrm{~m}$, com pressão e vazão de trabalho de $206,8 \mathrm{kPa}$ e $200 \mathrm{~L} \mathrm{ha}^{-1}$, respectivamente. No período da aplicação o solo estava úmido, céu parcialmente nublado, brisa leve, temperatura do ar entre $26^{\circ}$ e $27^{\circ}$

Tabela 3 - Tratamentos avaliados no experimento de seletividade e eficácia de controle de herbicidas na cultura da mandioca, BRS Purus. Iranduba, 2018

\begin{tabular}{lcc}
\hline \multicolumn{1}{c}{ Tratamentos } & Dose $\left(\mathbf{g}\right.$ de $\left.\mathbf{i . a} \mathbf{~ h a}^{-1}\right)$ & Aplicação \\
\hline Clomazone & 1080 & PRE \\
Clomazone - Capina 60 DAP & 1080 & PRE \\
Clomazone - Clethodim 60 DAP & $1080-108$ & PRE - POS \\
Clomazone - Glifosato 60 DAP & $1080-1440$ & PRE - POS \\
Diuron & 2500 & PRE \\
Diuron - Capina 60 DAP & 2500 & PRE \\
Diuron - Clethodim 60 DAP & $2500-108$ & PRE - POS \\
Diuron - Glifosato 60 DAP & $2500-1440$ & PRE - POS \\
Oxadiazon & 1000 & PRE \\
Oxadiazon - Capina 60 DAP & 1000 & PRE \\
Oxadiazon - Clethodim 60 DAP & $1000-108$ & PRE - POS \\
Oxadiazon - Glifosato 60 DAP & $1000-1440$ & PRE - POS \\
Testemunha capinada - 30, 60, 90 e 120 DAP & - & - \\
Testemunha sem capina & - & - \\
\hline
\end{tabular}

Clomazone (concentrado emulsionável, 500 $\mathrm{g} \mathrm{L}^{-1}$ ); Diuron (suspensão concentrada, $500 \mathrm{~g}$ $\mathrm{L}^{-1}$ ); Oxadiazon (concentrado emulsionável, 250g $\mathrm{L}^{-1}$ ); Clethodim (concentrado emulsionável, 240 $\mathrm{g} \mathrm{L}^{-1}$ ); Glifosato (concentrado solúvel, $480 \mathrm{~g} \mathrm{~L}^{-1}$ do sal de isopropilamina); i.a - ingrediente ativo; PRE - pré-emergência; POS - pós-emergência; DAP - dias após o plantio.

Agrotrópica 33(1) 2021
C e umidade relativa do ar acima de $80 \%$. A aplicação dos herbicidas em POS foi realizada aos 60 DAP, empregando o mesmo equipamento, com pressão e vazão constantes de $193 \mathrm{kPa}$ e $175 \mathrm{~L} \mathrm{ha}^{-1}$, respectivamente. No período da aplicação o solo estava úmido, o céu nublado, brisa leve, temperatura do ar de $26^{\circ} \mathrm{C}$ e umidade relativa do ar acima de 80 $\%$, com as plantas daninhas sem sintomas de estresse hídrico. A pulverização do clethodim foi realizada sobre as plantas da cultura e a do glifosato de forma dirigida, abaixo do dossel da cultura e com protetor de deriva. No momento da aplicação dos herbicidas em POS as espécies daninhas dicotiledôneas tinham entre 6 e 10 folhas e as monocotiledôneas, mais de 6 perfilhos.

$\mathrm{Na}$ avaliação de seletividade as variáveis avaliadas foram os níveis de fitotoxicidade dos herbicidas aplicados em PRE aos 30, 45 e 60 dias após a aplicação (DAA), aos 7,14 e 28 DAA para os herbicidas aplicados em POS, a população de plantas por ocasião da colheita e produtividade de raízes. Para essas avaliações de fitotoxicidade foi adotada escala percentual, onde zero significa ausência de sintomas e $100 \%$, morte das plantas (Frans et al., 1986).

$\mathrm{Na}$ avaliação de eficácia de controle as variáveis avaliadas foram a massa de matéria seca (MMS) de plantas de Paspalum virgatum e de outras espécies daninhas aos 50 e 150 DAP e a produtividade de raízes. As plantas daninhas foram coletadas com emprego de uma armação quadrada vazada de 1 $m$ de lado. A parte aérea das plantas daninhas contidas pela armação foram cortadas a 0,02 $m$ de altura em relação ao solo e levadas para laboratório, lavadas em água corrente para retirada de partículas de solo e secas em estufa com circulação forçada de ar a $65^{\circ} \mathrm{C}$ até atingirem peso constante. A colheita das raízes ocorreu aos 14 meses após o plantio, com limpeza manual das raízes para retirada de solo e pesagem em campo.

Os dados experimentais foram submetidos a análises de 
normalidade (Lilliefors) e de homogeneidade (Cochran) de variâncias dos erros experimentais e de variância. As médias de tratamentos foram comparadas pelo teste de Tukey a $5 \%$ de probabilidade. As análises estatísticas foram realizadas com o programa Genes (Cruz, 2013).

\section{Resultados e Discussão}

Os dados tiveram distribuição normal e não houve necessidade de transformação dos mesmos.

$\mathrm{Na}$ Tabela 4 estão apresentados os níveis de significância dos quadrados médios das variáveis avaliadas no experimento.

Os tratamentos não influenciaram o nível de fitotoxicidade dos herbicidas aplicados em PRE aos 60 DAA e a população de plantas e a produtividade de raízes na avaliação de seletividade.

Nas Tabelas 5 e 6 estão apresentados os valores médios dos níveis de fitotoxicidade das plantas da BRS Purus pelos herbicidas testados.

Os herbicidas aplicados em PRE provocaram sintomas de fitotoxicidade até 45 DAA (Tabela 5) porém, considerados leves e moderados de acordo com a escala adotada na avaliação. Aos 60 DAA os níveis de fitotoxicidade não diferiram da testemunha.

Aos 30 DAA os níveis de fitotoxicidade registrados nas plantas de BRS Purus com aplicação do clomazone foram mais baixos em relação ao herbicida diuron e oxadiazon, destacando que este herbicida é registrado para emprego na cultura da mandioca no Brasil (Agrofit, 2021). O clomazone provocou branqueamento leve do limbo foliar, semelhante ao relatado por Costa et al. (2013a) em plantas da cultivar 'Baianinha' após pulverização deste herbicida com doses de 900 e 1080 g de i.a ha ${ }^{-1}$ em POS. Scariot et al. (2013) não relataram sintomas de fitointoxicação de plantas da cultivar 'Cascuda' com aplicação do clomazone

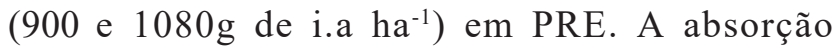
do clomazone ocorre nos meristemas apicais, principalmente das raízes, favorecida por maior umidade do solo e baixos conteúdos de argila e de matéria orgânica (Lee et al., 2004). Nas espécies sensíveis ocorre a conversão do clomazone em 5cetoclomazone, inibindo a atividade da enzima deoxixilulose-5-fosfato sintase (Ferhatoglu \& Barret, 2006) e a síntese de carotenóides, pigmentos protetores do aparelho fotossintético das plantas contra o excesso de energia luminosa e que resulta na fotodegradação da clorofila (Dayan \& Zaccaro, 2012). Nas plantas tolerantes o clomazone é hidroxilado para a forma 5-OH-clomazone e não tem ação herbicida (Ferhatoglu \& Barret, 2006).

O diuron provocou clorose moderada nas folhas da cultivar BRS Purus (Tabela 5), sintoma relatado também em plantas das cultivares 'Fécula Branca' e 'Fibra' com aplicação deste herbicida em PRE com doses de 400 ou $800 \mathrm{~g}$ de i.a ha ${ }^{-1}$ até 60 DAA (Biffe et al., 2010). Silva et al. (2012a) avaliaram a seletividade do diuron $\left(2500 \mathrm{~g}\right.$ de i.a ha $\left.{ }^{-1}\right)$ aplicado em POS para a cultivar IAC-12 e verificaram fitointoxicação leve, com redução da intensidade a partir dos 21 DAA. O diuron inibe o transporte de elétrons ao nível do Fotossistema II, resultando em formação de espécies reativas de oxigênio e oxidação de membranas dos tilacóides das clorofilas (Mestankova et al., 2011).

Tabela 4 - Níveis de significância dos quadrados médios das variáveis avaliadas no experimento de seletividade de herbicidas e eficácia de controle de plantas daninhas na cultura da mandioca, BRS Purus. Iranduba, 2018

\begin{tabular}{|c|c|c|c|c|c|c|c|c|c|c|c|c|c|c|}
\hline \multirow{2}{*}{ FV } & \multirow{2}{*}{ g.l } & \multicolumn{13}{|c|}{ Níveis de significância dos quadrados médios } \\
\hline & & Fpre1 & Fpre2 & Fpre3 & Fpos 1 & Fpos2 & Fpos3 & Pop & Prods & Msp1 & Mso1 & Msp2 & Mso2 & Prodec \\
\hline Tratamentos & 13 & $* *$ & $* *$ & n.s. & $* *$ & $*$ & $*$ & n.s. & n.s. & $*$ & $*$ & $* *$ & $* *$ & $*$ \\
\hline Erro & 40 & - & - & - & - & - & - & - & - & - & - & - & - & - \\
\hline Total & 56 & - & - & - & - & - & - & - & - & - & - & - & - & - \\
\hline
\end{tabular}

FV - fonte de variação; g. 1. - graus de liberdade; Fpre1 - fitotoxicidade pré-emergncia (PRE) 30 dias após a aplicação (DAA); Fpre2 - fitotoxicidade PRE 45 DAA; Fpre3 - fitotoxicidade PRE 60 DAA; Fpos1 - fitotoxicidade pós-emergência (POS) 7 DAA; Fpos2 - fitotoxicidade POS 14 DAA; Fpos3 - fitotoxicidade POS 28 DAA; Pop - população de plantas na avaliação de seletividade; Prods - produtividade de raízes na avaliação de seletividade; Msp1 - massa de matéria seca (MMS) de Paspalum virgatum 50 dias após o plantio (DAP); Mso1 - MMS de outras espécies daninhas 50 DAP; Msp2 - MMS de Paspalum virgatum 150 DAP; Mso2 - MMS de outras espécies daninhas 150 DAP; Prodec - produtividade de raízes na avaliação de eficácia de controle. **, * e n.s. significativo a $1 \%$ e $5 \%$ de probabilidade e não significativo, respectivamente. 
Tabela 5 - Níveis de fitotoxicidade (\%) de plantas de mandioca, BRS Purus, com aplicação de herbicidas em pré-emergência. Iranduba, 2018

\begin{tabular}{|c|c|c|c|}
\hline \multirow{2}{*}{ Tratamentos } & \multicolumn{3}{|c|}{ Níveis de fitotoxicidade (\%) } \\
\hline & $30 \mathrm{DAA}$ & $45 \mathrm{DAA}$ & $60 \mathrm{DAA}$ \\
\hline Clomazone & $13,8 \mathrm{C}$ & $8,0 \mathrm{~b}$ & 2,8 \\
\hline Clomazone - Capina & $11,0 \mathrm{C}$ & $6,8 \mathrm{~cd}$ & 2,0 \\
\hline Clomazone-Clethodim & $15,3 \mathrm{Bc}$ & $6,5 \mathrm{bcd}$ & 2,5 \\
\hline Clomazone - Glifosato & $10,8 \mathrm{C}$ & 7,0 bcd & 2,0 \\
\hline Diuron & 29,9 A & $16,5 \mathrm{a}$ & 4,5 \\
\hline Diuron - Capina & $32,5 \mathrm{~A}$ & $16,5 \mathrm{a}$ & 5,0 \\
\hline Diuron - Clethodim & 30,0 A & $15,3 \mathrm{ab}$ & 4,8 \\
\hline Diuron - Glifosato & $28,3 \mathrm{~A}$ & $14,5 \mathrm{ab}$ & 5,3 \\
\hline Oxadiazon & 26,3 A & 7,0 bcd & 4,0 \\
\hline Oxadiazon - Capina & $24,0 \mathrm{Ab}$ & $6,3 \mathrm{bcd}$ & 2,3 \\
\hline Oxadiazon-Clethodim & $28,5 \mathrm{~A}$ & $6,8 \mathrm{~cd}$ & 2,0 \\
\hline Oxadiazon - Glifosato & $29,5 \mathrm{~A}$ & 7,3 bcd & 2,8 \\
\hline Testemunha capinada & $0 \quad \mathrm{D}$ & $0 \quad \mathrm{~d}$ & 0 \\
\hline C.V. $(\%)$ & 19,25 & 11,63 & 8,59 \\
\hline D.M.S. & 9,7 & 7,7 & 5,6 \\
\hline
\end{tabular}

DAA - dias após a aplicação. Médias seguidas por letras distintas nas colunas diferem significativamente entre si pelo teste de Tukey a $5 \%$ de probabilidade.

Tabela 6 - Níveis de fitotoxicidade (\%) de plantas de mandioca, BRS Purus, com aplicação de herbicidas em pós-emergência. Iranduba, 2018

\begin{tabular}{|c|c|c|c|}
\hline \multirow{2}{*}{ Tratamentos } & \multicolumn{3}{|c|}{ Níveis de intoxicação (\%) } \\
\hline & $7 \mathrm{DAA}$ & 14 DAA & $28 \mathrm{DAA}$ \\
\hline Clomazone-Clethodim & $2,0 \mathrm{~B}$ & $1,0 \mathrm{~b}$ & $1,0 \mathrm{~b}$ \\
\hline Clomazone - Glifosato & $38,3 \mathrm{~A}$ & 22,8 a & $10,3 \mathrm{a}$ \\
\hline Diuron - Clethodim & $1,8 \mathrm{~B}$ & $1,0 \mathrm{~b}$ & $1,0 \mathrm{~b}$ \\
\hline Diuron - Glifosato & $39,0 \mathrm{~A}$ & 19,0 a & $12,8 \mathrm{a}$ \\
\hline Oxadiazon-Clethodim & $2,0 \mathrm{~B}$ & $1,0 \quad b$ & $1,0 \mathrm{~b}$ \\
\hline Oxadiazon - Glifosato & $36,0 \mathrm{~A}$ & 15,3 a & 9,0 a \\
\hline Testemunha capinada & $0 \quad \mathrm{~B}$ & $\begin{array}{ll}0 & b\end{array}$ & $0 \quad b$ \\
\hline C.V. $(\%)$ & 15,63 & 10,99 & 7,32 \\
\hline D.M.S. & 21,6 & 12,4 & 5,7 \\
\hline
\end{tabular}

DAA - dias após a aplicação. Médias seguidas por letras distintas nas colunas diferem significativamente entre si pelo teste de Tukey a $5 \%$ de probabilidade.

O oxadiazon provocou clorose leve das folhas das plantas da BRS Purus (Tabela 5). Em avaliações de seletividade do oxadiazon em outras culturas foram descritos como sintomas de fitointoxicação redução de altura de plantas de sorgo (Ishaya, Dadari \& Shebayan, 2007), clorose em folhas cotiledonares de feijão-caupi (Fontes et al., 2010) e redução do acúmulo de massa seca de parte aérea e de raízes em arroz
(Chauhan \& Johnson, 2011). O oxadiazon inibe a atividade da enzima protoporfirinogênio oxidase (PROTOX), resultando em acúmulo de protoporfirina IX no citosol e formação de espécies reativas de oxigênio e oxidação de ácidos graxos de membranas celulares (Silva, Ferreira e Ferreira, 2007).

A aplicação em POS do clethodim não provocou sintomas de fitotoxicidade nas plantas de BRS Purus (Tabela 6). O clethodim é um herbicida que inibe a atividade da enzima acetilcoenzima A carboxilase (ACCase) e a síntese de lipídeos nas plantas da família Poaceae (Délye et al., 2005), sendo muito seletivo para culturas eudicotiledôneas. Costa et al. (2013b) relataram que a pulverização de clethodim (120g i.a ha-1) em POS sobre plantas da cultivar 'Cascuda' não provocou nenhum sintoma de intoxicação. Por sua vez, a pulverização do glifosato resultou em níveis de fitotoxicidade nas plantas da cultura significativamente superiores aos do clethodim e da testemunha capinada (Tabela 6).

Os sintomas de fitointoxicação do glifosato foram clorose leve e afilamento de alguns lobos foliares no sentido de seu eixo longitudinal. Mesmo com a aplicação dirigida e uso de protetor provavelmente ocorreu deriva da solução herbicida resultando nos níveis de fitotoxicidade. Trabalhos conduzidos em condições controladas para avaliação da seletividade de glifosato a cultivares de mandioca tiveram resultados distintos. Ferreira (2015) pulverizaram glifosato com dose de $360 \mathrm{~g}$ de i.a ha ${ }^{-1}$ em plantas da cultivar IAC 12 com 45 DAP e 0,2 m de altura e relataram morte das plantas aos 23 DAA. Vitorino, Souza e Vera (2016) avaliaram a seletividade do glifosato para a cultivar Safrinha em condição controlada e relataram que o herbicida aplicado com dose de $720 \mathrm{~g}$ de i.a ha-1 ${ }^{-1}$ nas plantas com 90 dias de idade provocou sintomas leves de fitointoxicação e não interferiu na altura de plantas, diâmetro de caule, formação de folhas e no acúmulo de massa seca pelas plantas em relação à testemunha sem aplicação do herbicida. O glifosato inibe a atividade da enzima 5-enolpiruvilshiquimato-3fosfato sintase, o que impede a síntese de aminoácidos aromáticos e de proteínas, além de resultar em escassez de compostos carbônicos para outras rotas metabólicas nas plantas (Duke \& Powles, 2008).

Na Tabela 7 estão apresentados os valores médios da população de plantas e da produtividade de raízes da cultivar BRS Purus submetida aos tratamentos na avaliação de seletividade. 
Tabela 7 - População de plantas (plantas ha-1) e produtividade de raízes ( $\left(\mathrm{tha}^{-1}\right)$ de mandioca, BRS Purus, obtidas na avaliação de seletividade de herbicidas. Iranduba, 2018

\begin{tabular}{lcc} 
Tratamentos & $\begin{array}{c}\text { População de } \\
\text { plantas } \\
\text { (plantas ha }\end{array}$ & $\begin{array}{c}\text { Produtividade } \\
\text { de raízes } \\
\text { (t ha-1) }^{-1}\end{array}$ \\
\hline Clomazone & 12277 & 40,2 \\
Clomazone - Capina & 12054 & 39,3 \\
Clomazone-Clethodim & 11830 & 44,8 \\
Clomazone-Glifosato & 12054 & 40,3 \\
Diuron & 12054 & 41,1 \\
Diuron-Capina & 11161 & 42,9 \\
Diuron-Clethodim & 12277 & 41,0 \\
Diuron- Glifosato & 11161 & 39,1 \\
Oxadiazon & 11161 & 42,4 \\
Oxadiazon - Capina & 11830 & 40,9 \\
Oxadiazon-Clethodim & 12054 & 40,7 \\
Oxadiazon-Glifosato & 11161 & 43,9 \\
Testemunha capinada & 12054 & 43,0 \\
C.V. (\%) & 13,1 & 16,4 \\
D.M.S. & 3332 & 15,8 \\
\hline
\end{tabular}

A pulverização dos herbicidas não influenciou a sobrevivência das plantas da cultivar e a produtividade, evidenciando assim as seletividades nas modalidades e condições de aplicação. Biffe et al. (2010) relataram que as cultivares 'Fécula Branca' e 'Fibra' não tiveram as suas populações afetadas pela pulverização em PRE do diuron $\left(800 \mathrm{~g}\right.$ de i.a ha $\left.{ }^{-1}\right)$, porém, o herbicida provocou redução de produtividade da cultivar 'Fécula Branca'.

$\mathrm{Na}$ Tabela 8 estão apresentados os valores médios da massa matéria seca (MMS) de plantas de Paspalum virgatum e outras espécies daninhas e da produtividade de raízes obtidos com as ações de controle avaliadas no experimento.

Por ocasião da primeira coleta de plantas daninhas (50 DAP) verificou-se que Paspalum virgatum era responsável por cerca de $70 \%$ da cobertura da superfície do solo promovida por plantas daninhas. Assim, procedeu-se as coletas separadas de plantas de $P$. virgatum e de outras espécies.

As reduções de MMS de P. virgatum e de outras espécies daninhas (média das MMS de plantas daninhas dos 12 tratamentos) aos 50 DAP com a aplicação dos herbicidas em PRE em relação a testemunha sem capina foram de 72,4 e 72,7\%, respectivamente. As médias de MMS dos tratamentos com aplicação dos herbicidas foram significativamente semelhantes ao da testemunha capinada e menores do que o da testemunha sem capina. Na cultura da mandioca, de estabelecimento lento, com ciclo longo e capacidade pequena de sombreamento da superfície do solo, é desejável que os herbicidas aplicados em PRE tenham atividade no solo por tempo suficiente para exercer o controle de sementes e de plântulas das espécies daninhas e eliminar a interferência inicial. Segundo Silva, Vivian e Oliveira, 2007, o período de atividade de um herbicida no solo é definido como persistência, estimada pela sua meia-vida, que é o tempo necessário para que ocorra a dissipação de

Tabela 8 - Massa $\left(\mathrm{g} \mathrm{m}^{-2}\right)$ de matéria seca de plantas de Paspalum virgatum (Pasvi) e de outras espécies daninhas (Outras) e produtividade $\left(\mathrm{t} \mathrm{ha}^{-1}\right)$ de raízes de mandioca, BRS Purus, com pulverização de herbicidas. Iranduba, 2018

\begin{tabular}{|c|c|c|c|c|c|c|}
\hline \multirow{3}{*}{ Tratamentos } & \multicolumn{5}{|c|}{ Massa de matéria seca de plantas daninhas $\left(\mathrm{g} \mathrm{m}^{-2}\right)$} & \multirow{3}{*}{$\begin{array}{l}\text { Produtividade } \\
\qquad\left(\mathrm{t} \mathrm{ha}^{-1}\right)\end{array}$} \\
\hline & \multicolumn{2}{|c|}{$50 \mathrm{DAP}$} & \multicolumn{3}{|c|}{150 DAP } & \\
\hline & Pasvi & Outras & Pasvi & & Outras & \\
\hline Clomazone & $5,7 \mathrm{~b}$ & $2,2 \mathrm{~B}$ & 152,4 & $\mathrm{~b}$ & $30,1 \mathrm{~cd}$ & $19,5 \mathrm{~b}$ \\
\hline Clomazone - Capina & $3,4 \mathrm{~b}$ & $0,9 \mathrm{~B}$ & 31,1 & $\mathrm{c}$ & $18,5 \mathrm{~d}$ & 42,0 a \\
\hline Clomazone-Clethodim & $7,7 \mathrm{~b}$ & $4,1 \mathrm{~B}$ & 27,5 & $\mathrm{c}$ & 39,9 bc & 39,0 a \\
\hline Clomazone - Glifosato & $3,2 \mathrm{~b}$ & $1,8 \mathrm{~B}$ & 19,7 & $\mathrm{c}$ & $31,5 \mathrm{~cd}$ & 41,9 a \\
\hline Diuron & $3,8 \mathrm{~b}$ & $5,9 \mathrm{~B}$ & 117,3 & $\mathrm{~b}$ & 45,7 bc & $20,8 \mathrm{~b}$ \\
\hline Diuron - Capina & $5,6 \mathrm{~b}$ & $3,5 \mathrm{~B}$ & 16,5 & $\mathrm{c}$ & $24,8 \mathrm{~cd}$ & 43,9 a \\
\hline Diuron - Clethodim & $4,2 \mathrm{~b}$ & $1,4 \mathrm{~B}$ & 18,7 & $\mathrm{c}$ & $28,1 \mathrm{~cd}$ & 40,6 a \\
\hline Diuron - Glifosato & $5,5 \mathrm{~b}$ & $2,9 \mathrm{~B}$ & 23,5 & $\mathrm{c}$ & $15,3 \mathrm{~d}$ & 44,3 a \\
\hline Oxadiazon & $4,6 \mathrm{~b}$ & $1,6 \mathrm{~B}$ & 146,3 & $\mathrm{~b}$ & $49,3 \quad b$ & $23,8 \mathrm{~b}$ \\
\hline Oxadiazon-Capina & $3,9 \mathrm{~b}$ & $4,8 \mathrm{~B}$ & 19,4 & $\mathrm{c}$ & $26,6 \mathrm{~cd}$ & 39,7 a \\
\hline Oxadiazon-Clethodim & $3,7 \mathrm{~b}$ & $2,0 \quad \mathrm{~B}$ & 14,2 & $\mathrm{c}$ & 40,2 bc & 38,3 a \\
\hline Oxadiazon - Glifosato & $4,0 \mathrm{~b}$ & $1,3 \mathrm{~B}$ & 33,8 & $\mathrm{c}$ & $11,2 \mathrm{~d}$ & 42,8 a \\
\hline Testemunha capinada & $3,6 \mathrm{~b}$ & $1,1 \mathrm{~B}$ & 6,9 & $\mathrm{~d}$ & $13,8 \mathrm{~d}$ & 45,5 a \\
\hline Testemunha sem capina & $16,7 \mathrm{a}$ & 9,9 A & 353,7 & $\mathrm{a}$ & 185,6 a & $3,9 \mathrm{C}$ \\
\hline D.M.S. & 5,8 & 4,3 & 32,0 & & 16,4 & 12,7 \\
\hline $\mathrm{CV}(\%)$ & 24,9 & 31,8 & 45,3 & & 56,9 & 13,8 \\
\hline
\end{tabular}

DAP - dias após o plantio; Pasvi - Paspalum virgatum; Outras - demais espécies daninhas. Médias seguidas por letras distintas nas colunas diferem significativamente entre si pelo teste de Tukey a 5\% de probabilidade. 
metade da quantidade aplicada. A persistência do clomazone em condições aeróbicas pode variar de 47 dias em solo franco-argiloso (Tomco et al., 2010) a 117 dias em solo muito argiloso (Marulanda, 2017). Santiago et al. (2018) relataram que misturas de herbicidas contendo o clomazone $(1080 \mathrm{~g}$ de i.a ha $^{-1}$ ) tiveram persistência de 91 dias no controle de plantas daninhas (Amaranthus deflexus, Commelina benghalensis, Conyza sp., Heliotropium indicum, Mollugo vercillata, Cenchrus echinatus, Digitaria insularis e Eleusine indica) nas cultivares de mandioca Caravela e Pretinha cultivadas em um Latossolo Amarelo de textura franco-arenosa. A persistência do diuron pode variar de 49 dias em solos arenosos (Stork, Bennet \& Bell, 2008) a 91 dias em solos argilosos (Rocha et al., 2013). Biffe et al. (2007) verificaram que o diuron aplicado com doses de 625, 750 e $900 \mathrm{~g}$ de i.a ha ${ }^{-1}$ na cultura da mandioca em solo classificado como areia franca exerceu controle excelente de plantas daninhas (Acanthospermum hispidum, Amaranthus viridis, Bidens pilosa, Digitaria horizontalis, Sida cordifolia e Sida rhombifolia) até 45 dias após a pulverização do herbicida. Segundo Das, Debnath \& Mukherjee (2003) e Mendes et al. (2013) a persistência no solo do oxadiazon pode variar de 12 a 54 dias em solos argilosos. Na Tabela 1 verifica-se que o solo muito argiloso (teor de argila de $65 \mathrm{~g} \mathrm{~kg}^{-1}$ ) da área experimental foi uma condição que pode ter favorecido a atividade residual de todos os herbicidas aplicados em PRE.

Aos 150 DAP as reduções de MMS de $P$. virgatum com a pulverização isolada dos herbicidas clomazone, diuron e oxadiazon foram de 56,9, 66,8 e 58,6\%, respectivamente, e as de outras espécies daninhas 83,8 , 75,4 e $73,4 \%$, respectivamente. Essas reduções foram insuficientes para evitar a interferência das plantas daninhas na cultura e houve redução média de produtividade de $53 \%$. Isso ocorreu, provavelmente, em consequência da redução da atividade residual destes herbicidas no solo. O tempo de atividade no solo destes herbicidas foi insuficiente para eliminar a interferência das plantas daninhas durante o período crítico de prevenção da interferência da cultivar BRS Purus cultivada em terra firme, estimado entre 32 e 125 DAP (Fontes, Gonçalves e Morais, 2014). Quando foram associadas a capina e ou as aplicações dos herbicidas em POS aos 60 DAP aos herbicidas aplicados em PRE ocorreram reduções das MMS de P. virgatum de 93,6, 94,3 e 92,7\%, respectivamente, e as de outras espécies daninhas em 91,7, 80,6 e 89,6\%, respectivamente. Essas reduções de MMS possibilitaram eliminar a interferência negativa das plantas daninhas e atingir produtividades significativamente semelhantes à da testemunha capinada. Reshma et al. (2016) obtiveram maiores eficácia de controle de plantas daninhas e produtividade de raízes em lavoura de mandioca (cultivar precoce colhida aos cinco meses após o plantio) com pulverização de pendimethalin em PRE e capina aos 60 DAP ou pulverização dirigida de glifosato aos 30 DAP e capina aos 60 DAP. Nwagwu \& Asukwo (2019) obtiveram eficácia de controle de plantas daninhas acima de $90 \%$ com a associação dos herbicidas atrazine + metolachlor $(1,5$ $+1,2 \mathrm{~kg}$ de i.a ha ${ }^{-1}$ ) com duas capinas aos 84 e 120 DAP, resultando em produtividade de raízes equivalente à obtida com três capinas $(28,84$ e 120 DAP). A cultura da mandioca exige, na maioria das situações de cultivo, mais de uma operação de controle de plantas daninhas para que a interferência não provoque perdas de rendimento (Silva et al., 2012b; Fontes et al., 2014). A necessidade de mais de uma operação de controle é justificada em razão da ocorrência de vários fluxos de germinação de sementes de plantas daninhas presentes no solo durante o ciclo de cultivo da mandioca. Nas áreas de cultivo de mandioca no Amazonas o número de sementes de plantas daninhas é elevado, com mais de 50 milhões de sementes ha-1 na camada 0 a $5 \mathrm{~cm}$ de profundidade, possibilitando novas infestações ao longo do período crítico de competição (Costa, Mitja e Fontes, 2009).

\section{Conclusões}

Os herbicidas clomazone, diuron e oxadiazon, aplicados em PRE, e clethodim e glifosato, aplicados em POS aos 60 DAP, são seletivos para a cultivar de mandioca BRS Purus cultivada em Argissolo. A aplicação de clomazone, diuron ou oxadiazon associada à aplicação de clethodim ou glifosato permite obter níveis de controle de plantas daninhas e produtividades de raízes equivalente à realização de quatro capinas aos 30, 60, 90 e 120 DAP. 


\section{Literatura Citada}

AGROFIT. Sistema de agrotóxicos fitossanitários. 2021. Disponível em <http://agrofit.agricultura.gov.br/ agrofit_cons/principal_agrofit_cons $>$ Acesso em: 05 mar 2021.

ALVES FILHO, P. P. C. et al. 2015. Resposta da cultivar de mandioca Roxinha à adubação NPK. Raízes e Amidos Tropicais 11(1):1-7.

ASPIAZÚ, I. et al. 2010. Photosynthetic activity of cassava plants under weed competition. Planta Daninha, 28(número especial):963-968.

BANDEIRA, H. F. S. et al. 2016. Tolerância de mandioca a diferentes herbicidas aplicados em pós-emergência. Revista Brasileira de Herbicidas 15(3):241-250.

BIFFE, D. F. et al. 2007. Avaliação do herbicida diuron em pré-emergência no controle de seis plantas daninhas na cultura de Manihot esculenta. In: Congresso Brasileiro de Mandioca, 12. Paranavaí, PR, 2007. Resumos Expandidos. Revista Raízes e Amidos Tropicais (Volume Especial).

BIFFE, D. F. et al. 2010. Aplicação de herbicidas para dois cultivares de mandioca. Planta Daninha 28(4):807-816.

CHAUHAN, B. S.; JOHNSON, D. E. 2011. Growth responses of directed-seeded rice to oxadiazon and bispyribac-sodium in aerobic and saturated soils. Weed Science 59(1):119-122.

CHIKOYE, D. et al. 2006. Options for cogongrass (Imperata cylindrica) control in white guinea yam (Discorea rotundata) and cassava (Manihot esculenta). Weed Technology 20(3):784-792.

COSTA, J. R.; MITJA, D.; FONTES, J. R. A. 2009. Bancos de sementes de plantas daninhas em cultivos de mandioca na Amazônia central. Planta Daninha 27(4):665-671.

COSTA, N. V. et al. 2013a. Selectivity of clomazone and S-metolachlor applied after cassava pruning. Planta Daninha 31(4):979-985.

COSTA, N. V. et al. 2013b. Seletividade de herbicidas aplicados com óleo mineral na cultura da mandioca 'Cascuda'. Revista Brasileira de Herbicidas 12(3):251-259.

CRUZ, C. D. 2013. GENES A software package for analysis in experimental statistics and quantitative genetics. Acta Scientiarum 35(3):271-276.
DAS, A. C.; DEBNATH, A.; MUKHERJEE, D. 2003. Effect of the herbicides oxadiazon and oxyfluorfen on phosphates solubilizing microrganisms and their persistence in rice fields. Chemosphere 63(3):217-221.

DAYAN, F. E.; ZACCARO, M. L. M. 2012. Chlorophyll fluorescence as a marker for herbicide mechanisms of action. Pesticide Biochemistry and Physiology 102(3):189-197.

DÉLYE, C. et al. 2005. Molecular bases for sensitivity to acetyl-coenzyme A caboxilase inhibitors in blackgrass. Plant Physiology 137(3):794-806.

DIAS, M. C. A. 2015. Contribuição da pesquisaexperimentação e o conhecimento tradicional para o cultivo da mandioca no Amazonas. Terceira Margem Amazônia 1(5):143-154.

DUKE, S. O.; POWLES, S. B. 2008. Glyphosate: a oncein-a-century herbicide. Pest Management Science 64(4):319-325.

FARALDO, M. I. F. et al. 2000. Variabilidade genética de etnovariedades de mandioca em regiões geográficas do Brasil. Scientia Agricola 57(3):499-505.

FOOD AND AGRICULTURE ORGANIZATION - FAO. 2013. Cassava's huge potential as 21 st Century crop. Disponível em < http://www.fao.org/news/story/en/ item/176780/icode> Acesso em: 02 mar 2021.

FERHATOGLU, Y.; BARRET, M. 2006. Studies of clomazone mode of action. Pesticide Biochemitry and Physiology 85(1):7-14.

FERREIRA, E. A. 2015. Respostas fisiológicas da mandioca à aplicação de herbicidas. Semina: Ciências Agrárias 36(2):645-656.

FONTES, J. R. A.; GONÇALVES, J. R. P.; MORAIS, R. R. 2010. Tolerância do feijão-caupi ao herbicida oxadiazon. Pesquisa Agropecuária Tropical 40(1):110-115.

FONTES, J. R. A. et al. 2014. Períodos de interferência de plantas daninhas na cultura da mandioca, variedade BRS Purus, em terra firme de Rio Preto da Eva, Amazonas. Manaus, Embrapa Amazônia Ocidental. Circular Técnica $n^{\circ} 47.8 p$.

FRANS, R. E. et al. 1986. Experimental design and techniques for measuring and analyzing plant responses to weed control pratices. In: Research Methods in Weed Science. Champaign, Southern Weed Science Society. pp.29-46. 
INSTITUTO BRASILEIRO DE GEOGRAFIA E ESTATÍSTICA - IBGE. 2018. Levantamento sistemático da produção agrícola. Disponível em: $<$ https://sidra.ibge.gov.br/tabela/188\#resultado $>$. Acesso em 31 maio. 2019.

ISHAYA, D. B.; DADARI, S. A.; SHEBAYAN, J. A. Y. 2007. Evaluation of herbicides for weed control in sorghum (Sorghum bicolor) in Nigeria. Crop Protection 26(11):1697-1701.

JAKOVAC, C. C. et al. 2016. Swidens under transition: consquences of agricultural intensification in the Amazon. Agriculture, Ecosystems \& Environment 218:116-125.

LEE, D. J. et al. 2004. Soil characteristics and water potential effects on plant-available clomazone in rice. Weed Science 52(2):310-318.

MARTINS, J. S. et al. 2018. Calcário e sua influência no cultivo de mandioca na Amazônia tocantina. Revista Brasileira de Agropecuária Sustentável 8(1):17-23.

MARULANDA, N. M. E. 2017. Sorção e persistência do clomazone em horizontes de um Latossolo Vermelho-Amarelo. Dissertação Mestrado. Viçosa, UFV. 60p.

MENDES, K. F. et al. 2013. Leaching and residual effects of oxadiazon as a function of the movement of water depth application and incorporation of soil organic matter. Journal of Food, Agriculture \& Environment 12(2):855-860.

MESTANKOVA, H. et al. 2011. Evolution of algal toxicity during (photo)oxidation degradation of diuron. Aquatic Toxicology 101(2):466-473.

MUELLER-DOMBOIS, D.; ELLENBERG, H. 1974. Aims and methods of vegetation ecology. New York, John Willey \& Sons. 547p.

NWAGWU, F. A.; ASUKWO, U. I. 2019. Effects of integrated weed management on tuber yield of cassava (Manihot esculenta Crantz). Journal of Research in Weed Science 2(1):1-15.

OLIVEIRA JR., R. S. O.; INOUE, M. H. 2011. Seletividade de herbicidas para culturas e plantas daninhas. In: Oliveira Jr., R. S. O.; Constantin, J.; Inoue, M. H. Biologia e manejo de plantas daninhas. Curitiba, Omnipax. pp.243-261.

RESHMA, N. et al. 2016. Integrated weed management in cassava (Manihot esculenta Crantz). Journal of Root Crops 42(1):22-27.
ROCHA, P. R. R. et al. 2013. Meia-vida do diuron em solos com diferentes atributos químicos e físicos. Ciência Rural 43(11):1961-1966.

SANTIAGO, A. D. et al. 2018. Efficacy and selectivity of herbicides applied in cassava pre-emergence. Revista Caatinga 31(3):640-650.

SCARIOT, C. A. et al. 2013. Seletividade e eficiência de herbicidas aplicados em pré-emergência. Pesquisa Agropecuária Tropical 43(3):300-307.

SILVA,A. A.; FERREIRA, F. A.; FERREIRA, L. R. 2007. Herbicidas: classificação de mecanismos de ação. In: Silva, A. A.; Silva, J. F. Tópicos em manejo de plantas daninhas. Viçosa, Editora UFV. pp. 83-148.

SILVA, A. A.; VIVIAN, R.; OLIVEIRA Jr., R. S. O. 2007. Herbicidas: comportamento no solo. In: Silva, A. A.; Silva, J. F. Tópicos em manejo de plantas daninhas. Viçosa, Editora UFV. pp. 189-248.

SILVA, F. M. L. et al. 2009. Moléculas de herbicidas seletivos à cultura da mandioca. Trópica (Brasil) 3(2):61-72.

SILVA, D. V. et al. 2012a. Seletividade de herbicidas pós-emergentes na cultura da mandioca. Planta Daninha 30(4):835-841.

SILVA, D. V. et al. 2012 b. Manejo de plantas daninhas na cultura da mandioca. Planta Daninha 30(4):901910.

STORK, P. R.; BENNET, F. R.; BELL, M. J. 2008. The environmental fate of diuron under a conventional production regime in a sugarcane farm during the plant cane phase. Pest Management Science 64(9):954-963.

TOMCO, P. L. et al. 2010. Microbial degradation of clomazone under simulated california rice field conditions. Journal of Agricultural and Food Chemistry 58(6):3674-3680.

VIEIRA, E. A. et al. 2008. Variabilidade genética do banco de germoplasma de mandioca da Embrapa Cerrados acessada por meio de descritores morfológicos. Científica 36(1):56-67.

VITORINO, H. S.; SOUZA, C. C. S.; VERA, G. S. 2016. Seletividade da cultura da mandioca ao glyphosate aplicado em pós-emergência tardia. Congresso Internacional da Diversidade do Semiárido. CONIDIS. Campina Grande. 